\title{
Safety, efficacy and patient acceptability of the contraceptive and non-contraceptive uses of the LNG-IUS
}

This article was published in the following Dove Press journal:

International Journal of Women's Health

26 May 2009

Number of times this article has been viewed

\section{Paula H Bednarek \\ Jeffrey $T$ Jensen}

Department of Obstetrics and Gynecology, Oregon Health and

Science University, Portland, OR, USA
Correspondence: Paula H Bednarek Assistant Professor, Department of Obstetrics and Gynecology, Oregon Health and Science University, 3181 SW Sam Jackson Park Rd, UHN 50, Portland, OR 97239, USA

Tel + I 503-494-8842

Email bednarek@ohsu.edu

\begin{abstract}
Intrauterine devices (IUDs) provide highly effective, long-term, safe, reversible contraception, and are the most widely used reversible contraceptive method worldwide. The levonorgestrel-releasing intrauterine system (LNG-IUS) is a T-shaped IUD with a steroid reservoir containing $52 \mathrm{mg}$ of levonorgestrel that is released at an initial rate of $20 \mu \mathrm{g}$ daily. It is highly effective, with a typical-use first year pregnancy rate of $0.1 \%$ - similar to surgical tubal occlusion. It is approved for 5 years of contraceptive use, and there is evidence that it can be effective for up to 7 years of continuous use. After removal, there is rapid return to fertility, with 1-year life-table pregnancy rates of 89 per 100 for women less than 30 years of age. Most users experience a dramatic reduction in menstrual bleeding, and about $15 \%$ to $20 \%$ of women become amenorrheic 1 year after insertion. The device's strong local effects on the endometrium benefit women with various benign gynecological conditions such as menorrhagia, dysmenorrhea, leiomyomata, adenomyosis, and endometriosis. There is also evidence to support its role in endometrial protection during postmenopausal estrogen replacement therapy, and in the treatment of endometrial hyperplasia.
\end{abstract}

Keywords: levonorgestrel intrauterine system, LNG-IUS, intrauterine device, IUD, IUS

\section{Introduction}

Intrauterine devices (IUDs) provide highly effective, long-term, safe, reversible contraception and are the most widely used reversible contraceptive method worldwide. ${ }^{1}$ The levonorgestrel intrauterine system (LNG-IUS) is marketed under the brand name Mirena ${ }^{\circledR}$ (Bayer HealthCare), and in some European countries as Levonova ${ }^{\circledR}$. It was first introduced in Finland in 1990, and has since been approved for use in over 100 countries $^{2}$ and has over 10 million users. ${ }^{3}$

In 2007, IUDs were used by $16 \%$ of women worldwide aged 15 to 49 who are married or in a union. ${ }^{4}$ They were most commonly used in Asia, with over $40 \%$ of women using an IUD in China, the Democratic People's Republic of Korea, Kazakhstan and Uzbekistan. Between 30\% to 39\% of women used IUDs in Israel, Krygyzstan, Mongolia, Turkmenistan and Vietnam. This is in contrast to $14 \%$ overall use in Europe, with 21\% in Eastern Europe, 10\% in Northern Europe and only 6\% in Southern Europe. Estimated use is considerably lower in the United States, at only $1.8 \%$ of women.

This wide variation in IUD use reflects different patterns of availability, clinician and patient perceptions, and cultural influences. Concerns about pelvic inflammatory disease (PID) and possible infertility were related to complications with the Dalkon Shield from the 1970s, and have been disproved in regard to modern IUDs, including the LNG-IUS and copper T380A IUD. ${ }^{6}$ Because of the growing evidence 
of their safety and efficacy, ${ }^{5-8}$ and the non-contraceptive therapeutic benefits of the LNG-IUS, IUDs are undergoing a renaissance in Europe, the United States and elsewhere. In addition, liberalization of previously over restrictive labeling and medical protocols, including the United States Food and Drug Administration (FDA) product labeling, has helped to encourage more widespread use of IUDs in recent years. ${ }^{9}$ This article provides an overview of the wide range of contraceptive and non-contraceptive benefits of the LNG-IUS.

\section{The device}

The LNG-IUS is a T-shaped polyethylene device that is $32 \mathrm{~mm}$ long and $32 \mathrm{~mm}$ wide (Figure 1) - slightly smaller than the copper T380A device which is $36 \mathrm{~mm}$ long and $32 \mathrm{~mm}$ wide. It is sterilely packaged with a single use inserter. A monofilament polyethylene removal thread attached to a loop at the base of the stem, allows for identification of the
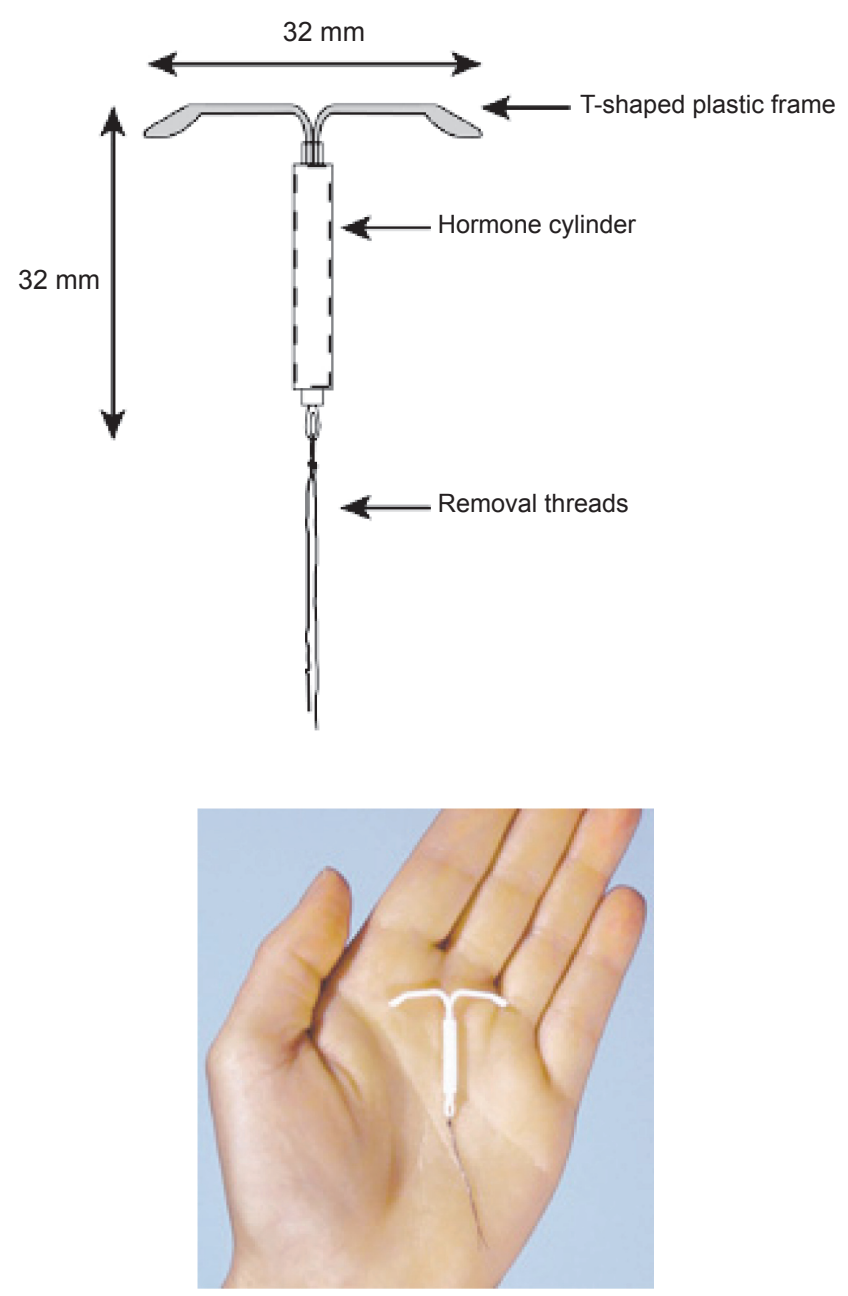

Figure I The levonorgestrel-releasing intrauterine system device. device and facilitates removal. The T-body contains barium sulfate, which makes it easily visible on X-ray.

The active ingredient, levonorgestrel (LNG), is dispersed in a silicone (polydimethylsiloxane) reservoir on the stem. This reservoir contains $52 \mathrm{mg}$ of LNG, and is covered by a polydimethylsiloxane membrane which allows for a controlled release of the hormone over time. The initial release rate of approximately $20 \mu \mathrm{g}$ per day occurs after insertion, and gradually decreases to approximately $10 \mu \mathrm{g}$ per day after 5 years of use. ${ }^{10}$

\section{Pharmacokinetics}

Although the mechanism of action of the LNG-IUS is primarily local, the LNG that is released within the uterus is swiftly absorbed into the systemic circulation. Maximum plasma levels are reached within a few hours after LNG-IUS insertion and plateau at 150 to $200 \mathrm{pg} / \mathrm{mL}(0.4$ to $0.6 \mathrm{nmol} / \mathrm{L})$ within the first few weeks. ${ }^{10}$ This is in contrast to the much higher plasma hormone levels of combined oral contraceptives, progesterone only pills and Norplant ${ }^{\circledR}$ (Figure 2). ${ }^{11}$ Plasma LNG levels from the LNG-IUS remain quite stable over time, but there is marked variation between individuals. ${ }^{12,13}$

\section{Changes in endometrial morphology}

In contrast to the relatively low plasma levels, the LNG-IUS achieves high concentrations of LNG in the endometrium and adjacent tissues. A small study that examined tissue concentrations found the average level of LNG in the endometrium to be approximately $808 \mathrm{ng} / \mathrm{g}$ in users of a prototype LNGIUS that released $30 \mu \mathrm{g} /$ day compared with $3.5 \mathrm{ng} / \mathrm{g}$ in a group of women taking oral contraceptive pills containing $250 \mu \mathrm{g} \mathrm{LNG.}{ }^{14}$ This allows the LNG-IUS to have profound endometrial effects that lead to the suppression of endometrial growth. Within 2 to 3 weeks after insertion, local LNG concentrations lead to decidualization of the stroma, mucosal thinning and an inactive endometrium. ${ }^{15} \mathrm{~A}$ foreign body reaction is characterized by an increase in inflammatory cells including neutrophils, lymphocytes, plasma cells and macrophages. ${ }^{16}$ These endometrial changes are finalized within 3 months after insertion of the LNG-IUS, ${ }^{16}$ and no further microscopic changes are identified within the endometrium thereafter. ${ }^{17}$ The sequence of these endometrial changes influences and explains the why the initial irregular bleeding pattern improves with time in most users.

\section{Effects on the ovary and pituitary}

The ovarian response to the LNG-IUS is directly dependent upon serum LNG levels. More than $50 \mu \mathrm{g}$ must be 


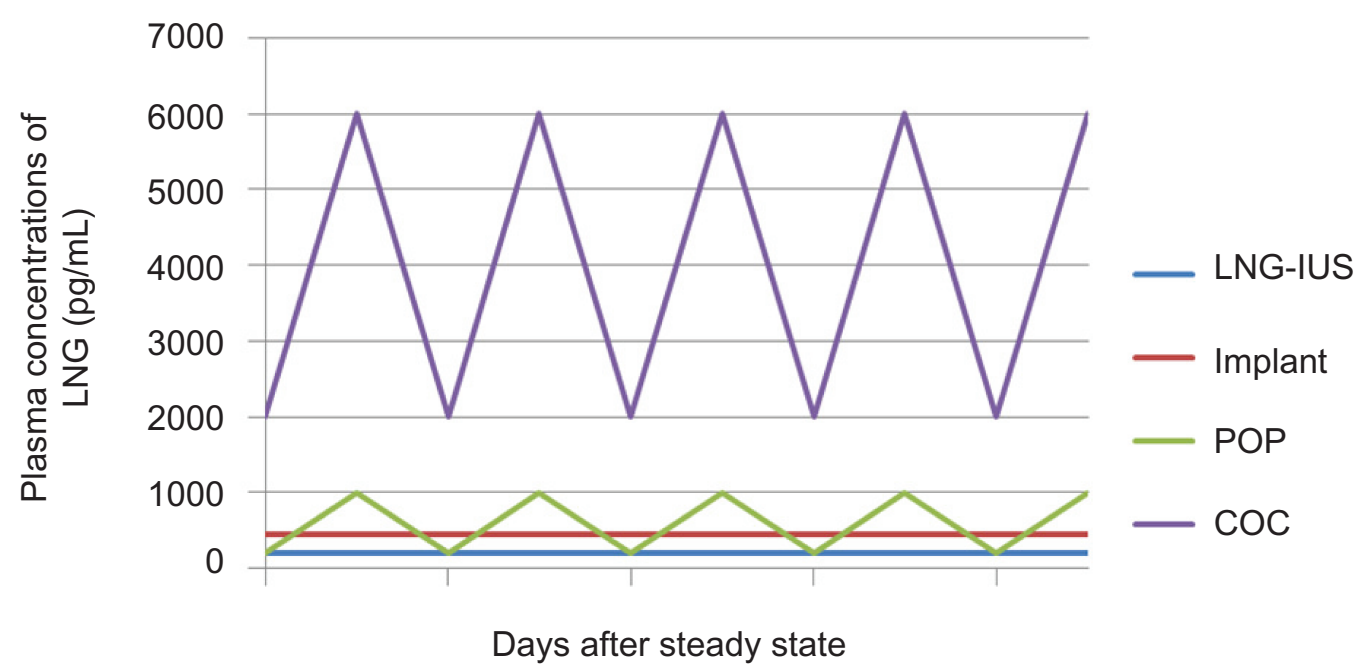

Figure 2 Comparison of plasma concentrations of different contraceptives containing levonorgestrel (LNG). From data of Nilsson et al" and Diaz et al. ${ }^{12}$ Abbreviations: LNG-IUS, levonorgestrel-releasing intrauterine system; COC, combined oral contraceptives; POP, progesterone only pills.

released daily for complete suppression of ovulation, while the LNG-IUS releases a maximum of $20 \mu \mathrm{g}$ per day. ${ }^{18}$ Serum LNG levels are highly variable between individuals, so ovulation is inhibited only in some women. After LNGIUS insertion, anovulatory cycles have been seen in 5\% to $15 \%$ of cycles, and correlate with higher circulating levels of LNG. ${ }^{19}$ These effects occur mostly during the first year of use, after which, the majority of cycles are ovulatory. ${ }^{20}$ Plasma estradiol (E2) and progesterone measurements are comparable to those of normally ovulating women. ${ }^{19}$

\section{LNG-IUS for contraception}

\section{Contraceptive mechanisms of action}

The contraceptive ability of the LNG-IUS comes from the local effects of LNG within the uterine cavity that primarily prevent fertilization. A common misconception, however, is that the primary mechanism of action of IUDs is abortifacient. As this concern represents a barrier to the use or recommendation of IUDs by some women and health care providers, the issue deserves thorough exploration.

Although interference with implantation plays a role in the postcoital effectiveness of copper IUDs, the available evidence suggests that this is not the mechanism in women using IUDs continuously. ${ }^{21}$ All IUDs produce a sterile foreign body reaction within the uterine cavity, which creates a hostile environment for sperm. ${ }^{22}$ The LNG-IUS thickens the cervical mucus (interfering with sperm passage), ${ }^{23}$ and inhibits sperm motility and function inside the uterus and the fallopian tubes (preventing fertilization). ${ }^{24}$ In addition, the LNG-IUS induces expres- sion of glycodelin A (anendometrial glycoprotein that inhibits sperm-egg binding) during the otherwise fertile midcycle, when this protein is normally absent. ${ }^{25}$ Studies on the recovery of eggs from women using IUDs compared with women using no method of contraception showed that normal fertilization did not occur in IUD users. ${ }^{21}$

These data show that contraceptive efficacy is related to preconceptual mechanisms, not implantation disruption. It can be concluded that when the rare normal fertilization does occur in a LNG-IUS user, it is associated with method failure.

\section{Efficacy of LNG-IUS for contraception}

Compared to other reversible methods, the LNG-IUS is among the most effective with a failure rate of $0.1 \%$ in the first year - similar to or even better than female sterilization (Figure 3). ${ }^{26}$ It is approved for 5 years of contraceptive use, and there is evidence that it can be effective for up to 7 years of continuous use.

In 2004 in a large retrospective study that was conducted in 17,360 Finnish women who used the LNG-IUS, all reported pregnancies were analyzed over 5 years (giving a total exposure of 58,600 woman-years). Sixty-four pregnancies occurred, which provided a cumulative pregnancy rate of $0.1 \%$ at 1 year and of $0.5 \%$ at 5 years. ${ }^{27}$ A Cochrane Review that evaluated 21 randomized controlled trials concluded that the effectiveness of the LNG-IUS is similar to copper IUDs with copper surface $>250 \mathrm{~mm}^{2}$, and significantly higher than IUDs with a copper surface of $<250 \mathrm{~mm}^{2}{ }^{28}$ There is also the suggestion that the LNG-IUS may be more effective than the 


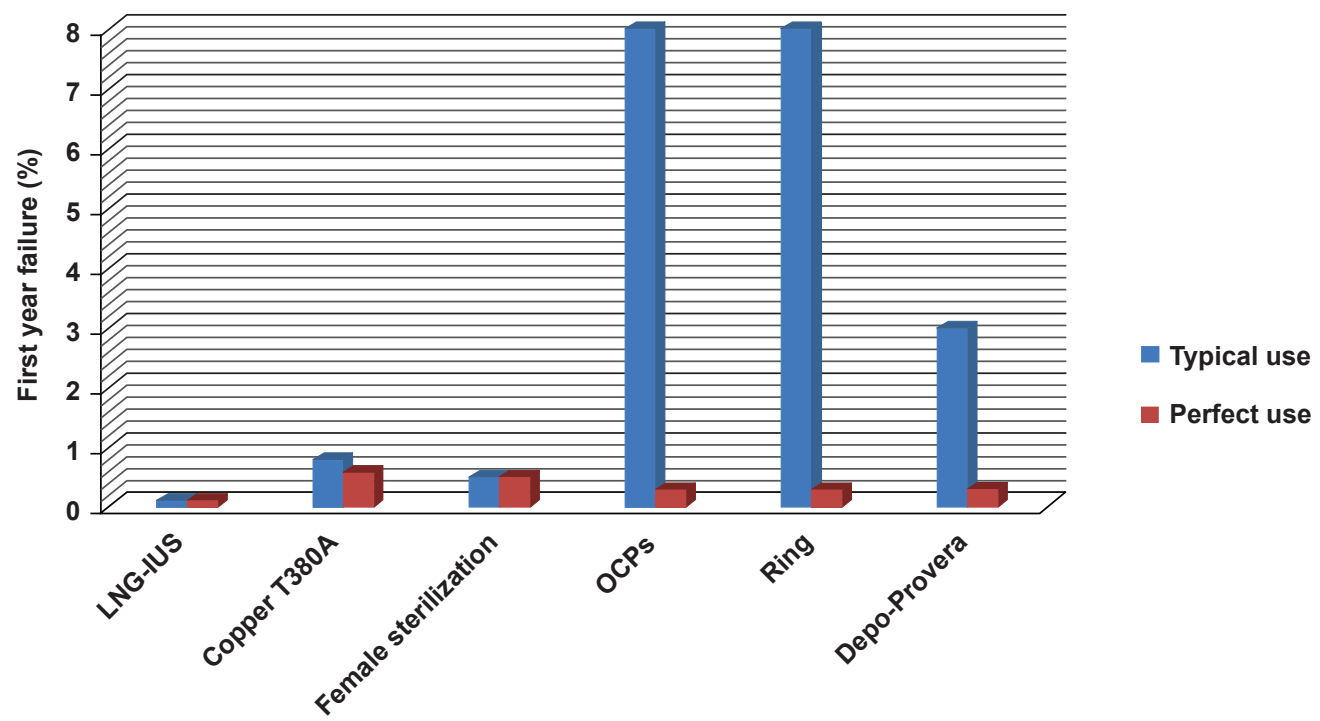

Figure 3 Typical use versus perfect use (first year failure rates). LNG-IUS provides highly effective contraception that is not user-dependent. From data of Trussell. ${ }^{124}$ Abbreviations: LNG-IUS, levonorgestrel-releasing intrauterine system; OCPs, oral contraceptive pills.

copper T380A; however, no randomized controlled trials have directly compared these IUDs long term.

The endometrial suppression has been observed up to 7 years after insertion, ${ }^{29}$ however the effect on cervical mucus may diminish after 5 years of use. ${ }^{30}$ Nonetheless, contraceptive efficacy appears to remain intact with up to 7 years of continuous use. In 1991, in a randomized multicenter study that was conducted in 2244 women, the cumulative pregnancy rate after 7 years of use was $1.1 \%$ for the levonorgestrel IUD and $1.4 \%$ for the copper T380A device. ${ }^{31}$ Two other studies that prospectively followed women using a LNG-IUS for 7 years reported no pregnancies, one among 293 women in Brazil, ${ }^{32}$ and the other among 82 women in Sweden. ${ }^{33}$ While a $1.1 \%$ pregnancy rate at 7 years is low compared with other reversible methods, this rate is double the efficacy achieved at 5 years. Therefore, replacement of the LNG-IUS at 5 years is recommended for women desiring continuing optimal contraception.

In addition, efficacy does not appear to be related to patient age. Other contraceptives, including other IUDs, have reported higher failure rates in younger women, mostly related to higher fertility rates with younger age. However, data indicate that this is not the case with the LNG-IUS - women can enjoy the same high contraceptive efficacy throughout their reproductive years. ${ }^{34}$

\section{Return to fertility}

The contraceptive actions of the LNG-IUS reverse soon after removal of the device. One-year life-table pregnancy rates after removal are 89 per 100 for women less than 30 years of age - rates are similar to women who had not been using any form of birth control. ${ }^{35-37}$

\section{Acceptability}

IUD users report higher satisfaction than users of other methods. Overall, 99\% of IUD users who continue with the method beyond 1 year report being "very satisfied" or "somewhat satisfied" with the method. ${ }^{38}$

Because most women using the LNG-IUS experience changes in menstrual bleeding patterns, long-term satisfaction requires that users find these menstrual changes acceptable or desirable. Removal rates attributed to bleeding irregularities or amenorrhea have varied greatly among study populations, with differing counseling quality as one contributing factor. ${ }^{33}$ Thorough counseling about expected changes in bleeding patterns before IUD insertion correlates with satisfaction and continuation rates after 1 year of use. ${ }^{39}$

A Finnish survey of over 16,000 women using the LNG-IUS found high continuation rates at 1 to 5 years: $93 \%$, $87 \%, 81 \%, 75 \%$ and $65 \%$, respectively. Rates were lowest for the 18- to 32-year age group and highest for the 39- to 48-year age group. ${ }^{40}$ Risk of premature removal was most strongly associated with excessive bleeding and spotting. It was also significantly related to symptoms of pelvic infection, depression, abdominal pain, and recurrent vaginal infection. In contrast, there was a significantly lower risk of removal among those who had occasional or no menstruation.

Studies in Brazil report a $90 \%$ satisfaction with the LNG-IUS, ${ }^{41}$ and $78 \%$ continuation at 1 year. ${ }^{42}$ In a survey 
of approximately 500 US women, satisfaction with clinician counseling and written product information was directly related to the length of LNG-IUS continuation at 12 months. ${ }^{43}$ This study also evaluated overall satisfaction with the LNG-IUS on a 7 point scale. The majority of women, $84.5 \%$, indicated a level or satisfaction with a value of 6 or 7 , while only $3.8 \%$ indicated low satisfaction, with a value of 1 or 2 . The most frequently reported reasons for liking the LNG-IUS were ease of use, reliability for birth control and increasingly lighter menstrual periods (reported by $29.9 \%, 29.2 \%$ and $21.8 \%$ of subjects, respectively). The most frequently reported reasons for disliking the LNG-IUS were "nothing," "other" and the "increase in spotting between periods;" these were reported by $46.2 \%, 12.7 \%$ and $12.1 \%$ of the subjects, respectively. Specific reasons included in the "other" category were cramping, spotting or bleeding, felt during intercourse by partner or subject, insertion procedure, and shortening or absence of menstrual periods.

\section{Potential barriers to use of LNG-IUS \\ Pelvic inflammatory disease (PID) and infertility}

One of the most persistent questions about IUDs is whether they increase the risk of PID. Overall, the rates of PID in the few available randomized control trials of IUDs do not exceed estimates for the general population. ${ }^{44}$ Combined data from 13 WHO clinical trials conducted in Africa, the Americas, Asia, and Europe found that the risk of developing PID was 6.3 times greater during the first 20 days after IUD insertion than at any later time..$^{45}$ After the first 20 days from insertion, the number of new PID cases occurring each year remained at a fairly constant low level, approximately 1.4 per 1000 woman-years, throughout 8 years of use. This low level is similar to or even lower than that among women in developed countries who do not use IUDs. ${ }^{46,47}$ In addition, some studies have suggested that the LNG-IUS may actually protect against upper genital tract infection, ${ }^{34,48}$ perhaps by thickening cervical mucus. A comparative study of the LNG-IUS versus the Nova-T copper IUD noted significantly lower rates of PID among LNG-IUS users at 3 and 5 years of follow-up. ${ }^{48} \mathrm{~A}$ second trial comparing the LNG-IUS and the copper T 380A IUD showed low terminations rates for PID/endometritis ( 0.7 per 100 years) with both devices. ${ }^{49}$

The polymicrobial nature of these early infections suggests that most occur due to contamination of the uterine cavity with endogenous flora during insertion. In addition, women with pre-existing asymptomatic chlamydia or gonorrhea have a higher risk of PID immediately after IUD insertion. ${ }^{50}$ Recommended steps to lower the risk of insertion related infection include careful screening and the use of multi-year devices (fewer insertions). Randomized trials of women at low risk for sexually transmitted infections have found no benefit of empiric antibiotic prophylaxis in reducing this insertion-associated risk. ${ }^{51}$ The role of sexually transmitted pathogens in later infections is independent of the device. In most cases of PID, treatment can be administered without removal of the device. ${ }^{52,53}$

Further reassurance of safety comes from a landmark 2001 case control study in nulliparous women who were seeking treatment for primary infertility that found no association between tubal infertility and past IUD use. ${ }^{54}$ In this study, 358 women with primary infertility who had documented tubal occlusion were compared with two control groups: 953 nulliparous women with primary infertility and no tubal occlusion (infertile controls), and 584 primigravid women (pregnant controls). Women with tubal occlusion reported prior IUD use at the same rate as infertile women without tubal occlusion or primigravid controls. Tubal infertility was associated with past chlamydia infection (as evidenced by chlamydia antibodies) and not with IUD use. This study supports the association between PID and infertility, and not IUD use and infertility.

\section{Ectopic pregnancy}

Considerable misunderstanding exists over the relationship between IUDs and ectopic pregnancy. Although the predominant mechanism for medicated IUDs is preconceptual, when fertilization does occur intrauterine effects or factors related to tubal transport may discourage normal implantation. For this reason, a disproportionate number of failures resulting in clinical pregnancies will be ectopics. However, the absolute number of ectopic pregnancies is lower among IUD users compared to non-contraceptors, because the overall pregnancy rate in IUD users is lower. In an evaluation of 17,360 women using the LNG-IUS (total exposure 58,600 woman-years), 108 reported a pregnancy, with 44 of these pregnancies found to be ectopic. ${ }^{40}$ An analysis of 42 randomized trials estimated ectopic rates per 1000 woman-years to be 0.5 for copper IUDs and 0.2 for the LNG-IUS,,$^{55}$ compared with 1.2 to 1.6 per 100 woman-years for the control population of sexually active women not using contraception. ${ }^{34}$ Importantly, past or prolonged use of an IUD does not increase risk of ectopic pregnancy. ${ }^{56}$

Since the evidence shows that both copper T380A and LNG-IUS users enjoy a substantial reduction in the overall risk of both ectopic and intrauterine pregnancy, they both 
should be considered appropriate choices for contraception in women with a history of a prior ectopic. Keeping in line with this information, restrictive labeling listing a history of ectopic pregnancy as a contraindication to use of the device was removed from the US package insert of the LNG-IUS in $2008 .^{10}$

\section{Perforation}

Perforation is a rare, but recognized potential complication of IUD use. It is estimated to occur at a frequency of 0 to 1.3 per 1000 insertions. ${ }^{57}$ If a perforation does occur and the device is within the peritoneal cavity, the manufacturer of the LNG-IUS recommends removal. ${ }^{10}$ If perforation is suspected at the time of insertion (difficult insertion, unusual heavy bleeding), the device should be immediately retrieved using the removal threads; most cases are asymptomatic and surgical exploration or hospitalization is not required. If the removal threads are not accessible, or if the perforation is recognized later, laparoscopy is the preferred surgical approach to removal. Perforation should always be considered in the differential for a patient that presents with a history of IUD placement, but no device present in the uterus on ultrasound exam. An abdominal X-ray can confirm the diagnosis. Surgical removal is not an emergency in the asymptomatic patient, but should be performed when convenient, as a benign natural history for an intrabdominal IUD cannot be assumed. A history of a perforation does not preclude later use of an IUD, but clinicians should allow 4 to 6 weeks for healing of the uterine wound, and ultrasound should be used to verify correct placement.

There have been 36 reports of fetal exposure to the LNG-IUS, 34 with intrauterine exposure and 2 with intraperitoneal exposure. ${ }^{58}$ Two of the 36 infants had congenital anomalies - one had a hypoplastic pulmonary artery, and the second had cystic hypoplastic kidneys. There is no indication that these two anomalies were related to exposure to levonorgestrel or to the physical device within the uterine cavity.

\section{Patient selection}

WHO Medical Eligibility Criteria (MEC) guidelines report few contraindications to IUD use, and suggest that most women can safely use the LNG-IUS (Table 1). ${ }^{5}$ Anyone at high risk for sexually transmitted infections (STIs) should be screened prior to or at the time of IUD insertion. Anyone not in a mutually monogamous relationship should utilize condoms for STI prevention in addition to the IUD for contraception.

A past history of PID in a woman with no current risk factors for STIs is not a contraindication to use. It is important to point out, however, that a prior episode of PID is associated with a $15 \%$ incidence of infertility. ${ }^{47}$ Future difficulty with pregnancy should not be attributed to the device. IUD insertion should be postponed for at least 3 months after an episode of PID or cervicitis, and negative cervical screening tests for gonorrhea and chlamydia should be obtained in that situation prior to insertion.

Although nulliparity was specifically removed as a contraindication from the US FDA labeling of the copper T380A in 2005, confusion exists around the language in the LNG-IUS package insert. The US LNG-IUS labeling was revised in $2008 .{ }^{10}$ Under indications and usage, it states that "Mirena is recommended for women who have had at least one child." However, nulliparity is not listed as a contraindication to use of the LNG-IUS in the package insert. Clinicians should be guided by the opinion of most experts and the WHO MEC that nulliparity is not a contraindication to use of either device. ${ }^{5,59}$ Nulliparous women may have higher

Table I WHO medical eligibility criteria contraindications to levonorgestrel-releasing intrauterine system insertion

(Category 4 or risk is unacceptable)

- Current pregnancy

- Current purulent cervicitis or pelvic infection (delay insertion until treatment is complete)

- Immediate post-septic abortion

- Current malignant gestational trophoblastic disease

- Current breast cancer

- Untreated cervical cancer

- Untreated endometrial cancer

- Unexplained vaginal bleeding

- Distorted uterine cavity (any congenital or acquired abnormality interfering with IUD insertion, including uterine fibroids)

- Known pelvic tuberculosis

Data from World Health Organization $2004 .^{5}$ 
rates of expulsion, bleeding and pain - probably related to uterine size. ${ }^{60}$ Small uterine size and a tight cervical canal may also make insertion more difficult. Still, the advantages of IUD use make it an appropriate choice for many nulliparous women.

Undiagnosed genital bleeding should be fully worked up prior to IUD insertion. Anatomic features that distort the uterine cavity, such as leiomyomata or Mullerian anomalies can increase expulsion or bleeding or make placement difficult.

Women who have illnesses that result in a serious immunocompromised state should be carefully monitored for infection if they choose to use an IUD. The risk of pregnancy should be weighed against the theoretical risk of infection. Data indicate that the IUD can safely be used in HIV-infected women who have access to medical care. IUD use is a WHO level 2 recommendation (benefit generally outweighs risks) for those at high risk for HIV, and for HIV-infected or AIDs patients clinically stable on antiretroviral therapy. ${ }^{5}$ LNG-IUS use provides the same general benefits as for immunocompetent women, ${ }^{61}$ and does not appear to have any drug interactions with antiretroviral therapies. ${ }^{62}$ In addition, IUD use in treated HIV patients does not appear to result in an increased risk in overall complications or infections beyond the insertion interval. ${ }^{63}$ It is a WHO level 3 recommendation (risk generally outweighs benefits) to insert an IUD in a patient with untreated AIDS. ${ }^{5}$

Women with diabetes also may safely use an IUD. ${ }^{5}$ No increased risk of infection or other complications have been observed. The LNG-IUS provides an attractive alternative to systemic hormonal methods, particularly in diabetics with vascular disease, smokers, and women with a history of thrombosis.

Women with thrombophilia or coagulopathies represent other important groups that can benefit from use of the LNGIUS. ${ }^{5}$ In general, the risk of pregnancy due to less effective contraception represents a much greater risk of thrombosis than use of LNG alone. ${ }^{64}$ Women with coagulopathies, including those on warfarin, experience a reduction in bleeding with the LNG-IUS. ${ }^{65}$

\section{Insertion timing}

In non-pregnant women, IUDs can be inserted during any phase of the menstrual cycle. ${ }^{66}$ Traditionally, physicians felt that it was best to insert an IUD either during or just after menstruation to ensure that the woman was not pregnant. However, limiting insertion to menses creates a barrier to IUD use. To maximize flexibility in scheduling and reduce the risk of luteal phase pregnancy that may not be detected by a sensitive urine pregnancy test, insertion of a LNG-IUS can occur anytime during the first half of the menstrual cycle in women not currently using contraception. Another option is that the patient may abstain from sex for at least 2 weeks prior to insertion to ensure that a luteal phase pregnancy will not be missed. There is no evidence that the LNG-IUS can be effective as emergency contraception, and it should not be used in this capacity.

Interestingly, insertion of a T-shaped IUD during the middle of the menstrual cycle has been shown to result in higher IUD continuation than menstrual insertion. A CDC review of more than 9000 T-200 IUD insertions showed that insertion from day 12 through 17 of the menstrual cycle (mid-cycle) resulted in fewer removals for expulsion, pain, bleeding, or unintended pregnancy during the first 2 months after IUD insertion. ${ }^{67}$ Since it takes a few days for the LNGIUS contraceptive effects to become established, patients should be cautioned to use a back-up method or remain abstinent for at least 7 days after midcycle placement.

Immediate insertion after vaginal delivery, cesarean section, or abortion also can be a safe option for women. With an experienced provider, immediate insertion following first trimester abortion has a reported expulsion rate of 5\% to $8 \%{ }^{68,69}$ compared to interval insertion expulsion rates of $4 \%$ to $5 \%$. $^{70,71}$ There are less data about insertion immediately after second trimester abortion, but there appears to be a somewhat higher expulsion rate than with first trimester abortion insertion. ${ }^{72}$ Studies are ongoing to evaluate the use of the LNG-IUS in this setting. After term delivery or cesarean section, the expulsion rate is approximately $12 \%$ to $15 \%$ when the IUD is placed within 10 to 30 minutes after delivery of the placenta. ${ }^{73,74}$ An IUD can be inserted at any time after a first trimester abortion, but should be delayed until after full uterine involution following a second trimester procedure, approximately 2 to 3 weeks. ${ }^{5}$ Postpartum insertion may be performed anytime after 4 weeks. ${ }^{5}$

\section{Insertion technique}

All prospective users should be thoroughly counseled regarding expected changes in bleeding patterns, and the insertion process. Most patients require no premedication for IUD insertion. Although the administration of a nonsteroidal anti-inflammatory (NSAID) agent such as ibuprofen 400 to $800 \mathrm{mg} 30$ to 60 minutes prior to the procedure is common, a large, well-designed randomized controlled trial found no benefit. ${ }^{75}$ Paracervical block may improve comfort, particularly with a closed cervix in a young, 
nulliparous woman or if dilation is needed. Recognizing that the paracervical block provides no uterine anesthesia, the discomfort of the block may outweigh the benefits, especially in parous women. For this reason, we discourage the routine use of paracervical block. Some women may have a vasovagal reaction to the passage of an instrument through the cervical canal. Paracervical block may be considered in patients with a history of a prior vasovagal reaction to cervical manipulation.

A Swedish study of 80 nulliparous women showed that providers found IUD insertion to be easier with the use of $400 \mu \mathrm{g}$ misoprostol sublingually 1 hour prior to IUD insertion. ${ }^{76}$ However, the majority of insertions in this study were rated as "easy," regardless of misoprostol use. Misoprostol may help with difficult IUD insertions, but there is no evidence to support its routine use, particularly since many women experience side effects with use. ${ }^{76}$

The package insert provides detailed information about insertion technique, and it is recommended that all providers undergo insertion training. ${ }^{10}$ The LNG-IUS has an inserter system that draws the arms into the insertion tube when the threads are pulled. The product packaging facilitates meticulous sterile technique during preparation of the device. Thereafter, a no-touch technique should be adopted to ensure that the device remains sterile.

The cervix is prepped and the anterior lip is then grasped with a tenaculum to straighten the cervical canal. With a retroverted uterus, grasping the posterior lip may facilitate this step. While most women tolerate the gentle application of the tenaculum, if severe pain occurs, the tenaculum is removed and local anesthetic can be administered. Sound the uterine cavity to determine the correct depth for insertion. The LNG-IUS has a small movable guide (flange) to mark correct depth along the insertion tube. While applying firm downward traction on the tenaculum to straighten the canal, pass the insertion tube into the uterine cavity. Take care to position the device so that the arms will lie in the horizontal plan of the uterus with the tips pointing into the cornual regions of the cavity when released. The insertion tube of the LNG-IUS is positioned until the flange is about 1.5 to $2 \mathrm{~cm}$ from the external os. At this point, the arms of the device are released from the insertion tube by pulling the slider back to a marked position on the insertion tube. After a slight delay to allow expansion of the arms, the inserter tube is gently pushed into the uterine cavity until the previously set flange guide touches the cervix. The LNG-IUS should now be at the fundal position, and can be released by pulling the slider down all the way. Confirm that the threads are released (this should occur automatically) and slowly withdraw the insertion tube.

Trim the threads to a length of approximately $3 \mathrm{~cm} .{ }^{10}$ Err on the side of extra tail length as the threads may always be trimmed later if they are too long. Long threads usually curl around the cervix into the fornices. Short threads tend to stick out from the os along the long axis of the cervix and may result in dyspareunia for the male partner.

Expected changes in bleeding and warning signs of infection or expulsion should be reviewed with all patients after insertion. Follow-up within the next month after insertion is not necessary for all patients - this can be individualized as needed. A follow-up appointment can allow for identification of expulsion or infection. It also can provide an opportunity for additional counseling about changes in bleeding, or other concerns which might result in premature removal of the device. While not recommended for all insertions, selective use of ultrasound following difficult insertions or in training settings can confirm correct placement of the device (Figure 4).

\section{Non-contraceptive uses of LNG-IUS}

While millions of women worldwide enjoy the contraceptive protection of the LNG-IUS, the non-contraceptive benefits of the system present unique opportunities for treatment of a variety of gynecologic problems in symptomatic patients with or without contraceptive needs. The health benefits of systemic hormonal contraception are well established. ${ }^{77}$ However, some women have contraindications to the use of estrogen, and not all women tolerate systemic progestin therapy. The LNG-IUS offers many of the same health benefits seen in users of systemic hormonal contraception - reduction in menstrual flow, dysmenorrhea, and pelvic pain symptoms. With the unique local delivery system of the LNG-IUS, LNG is released directly into the uterine cavity with low systemic levels. For most patients, this translates into fewer hormone-related symptoms. ${ }^{34}$ Currently, all non-contraceptive use of LNG-IUS is off-label in the US, but several of these uses are common approved indications in many other countries.

\section{Changes in bleeding patterns}

Use of the LNG-IUS results in endometrial thinning, glandular atrophy, stromal decidualization. ${ }^{17}$ During this process, spotting occurs frequently during the initial 4 to 6 cycles. However, after this transition, most women with normal menstrual cycles enjoy a reduction in both the number of menstrual bleeding days and the amount of objectively measured menstrual blood 


\section{A}

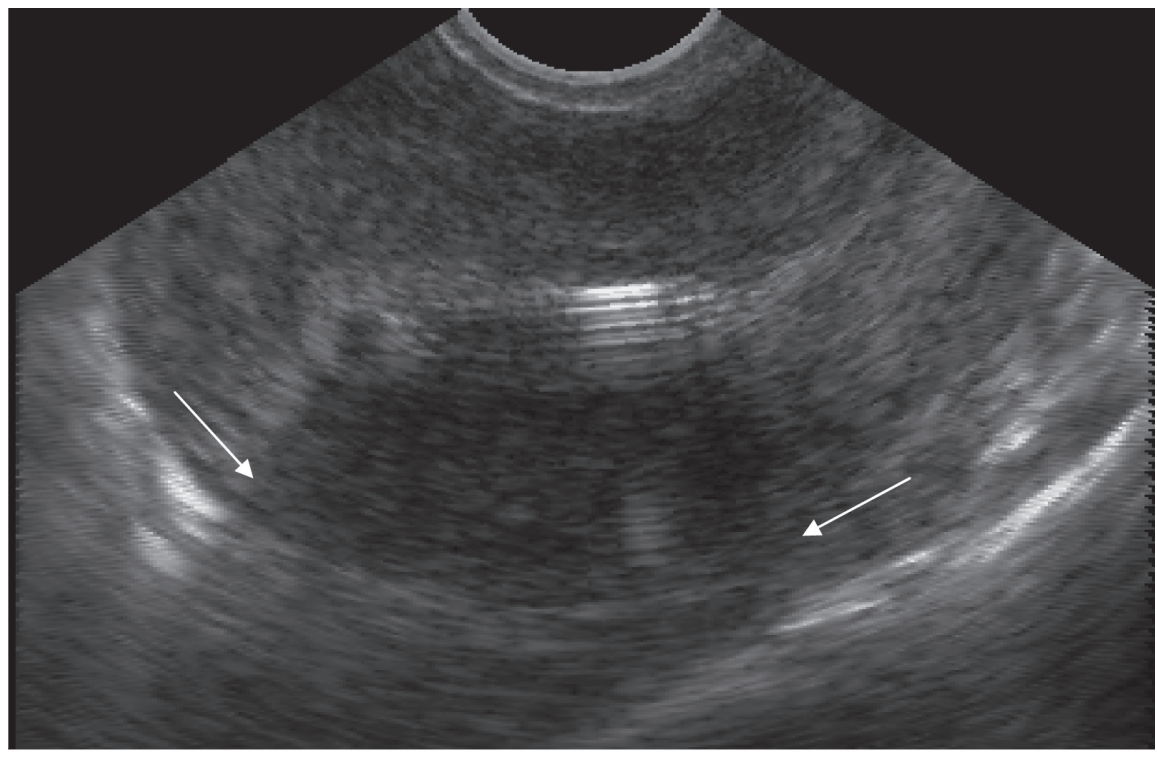

B

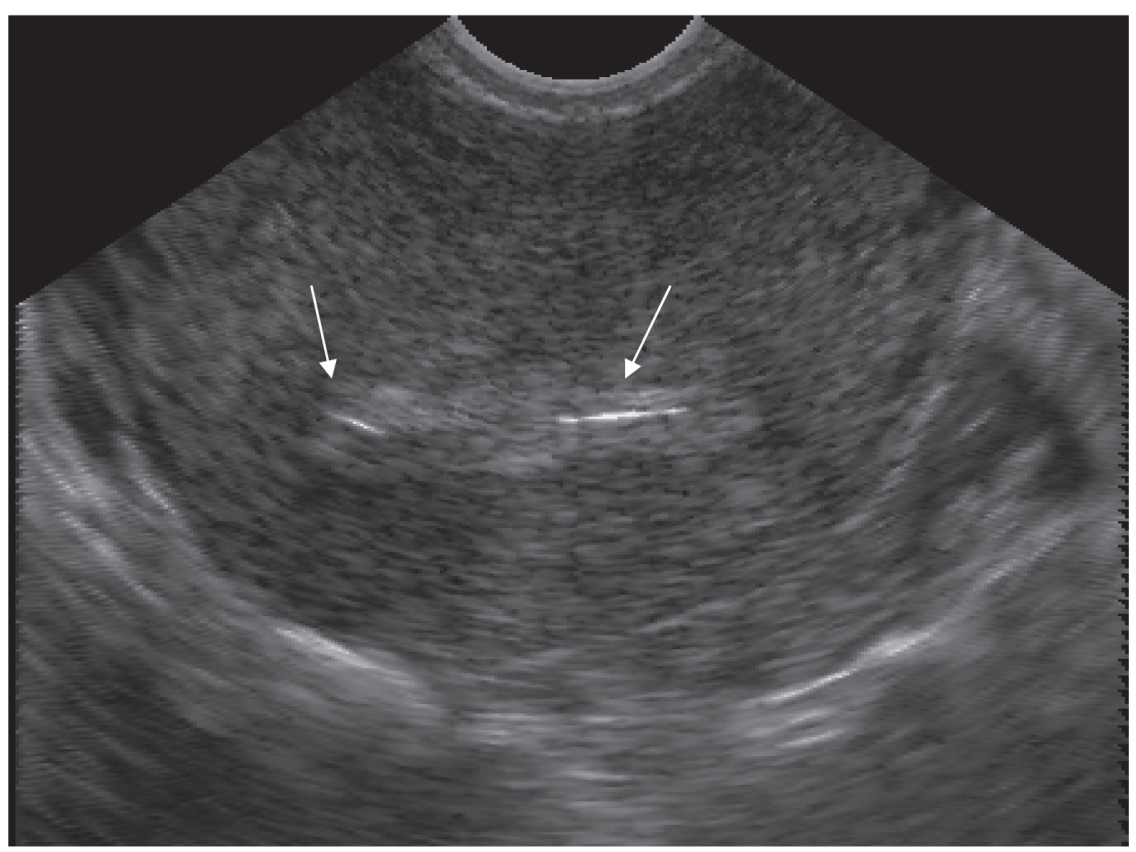

Figure 4 The levonorgestrel-releasing intrauterine system can be easily identified on transvaginal ultrasound. Note the shadowing caused by the stem of the device (arrows) in the anterior-posterior plane (panel A), and the T bar seen in the transverse orientation (panel B).

loss. ${ }^{78}$ Amenorrhea occurs in $15 \%$ to $20 \%$ of LNG-IUS users during the first year of use, and increases to $30 \%$ to $40 \%$ with longer durations of use. ${ }^{49,79}$ This is a desirable attribute for many women worldwide, even if eliminating their menses is more for convenience than to treat a gynecologic disorder. ${ }^{80}$

\section{Menorrhagia}

The LNG-IUS is approved in over 100 countries for the treatment of menorrhagia. ${ }^{81}$ It has been shown to outperform other hormonal and non-hormonal medical treatment options. ${ }^{82,83}$
A study of 34 Chinese women who failed conventional therapy for menorrhagia showed a $98 \%$ reduction in average menstrual blood loss 2 years after insertion of a LNG-IUS. Significantly, this improvement occurred early, with approximately one third of the women reporting amenorrhea by 6 months. ${ }^{84}$

In addition, a number of studies support LNG-IUS use as an effective, conservative treatment option that preserves reproductive function and avoids surgical risks and costs. A Finnish 5-year study comparing women with menorrhagia randomized to LNG-IUS or hysterectomy found similar 
measures of satisfaction and quality of life between treatment groups, and significantly lower costs in the LNG-IUS group. ${ }^{85}$ Comparisons of the LNG-IUS with endometrial resection or thermal balloon ablation have shown that both treatment options provide significant reduction in bleeding and similar patient satisfaction. ${ }^{86,87}$ A recent Cochrane review included five randomized trials directly comparing ablation to LNG-IUS for management of menorrhagia. ${ }^{87}$ Of these, two showed better controlled bleeding at 1 year with ablation, ${ }^{87,88}$ and three showed no difference in bleeding control at 1 to 3 years between these two options. A subsequent randomized trial of 83 women in New Zealand showed a better bleeding profile with LNG-IUS after 2 years compared to balloon ablation. ${ }^{89}$ All studies that have evaluated cost of surgical treatments compared to LNG-IUS have shown that the LNG-IUS is more cost-effective. ${ }^{87}$

\section{Anemia}

Since excessive menstrual bleeding is a common cause of anemia in fertile women, the profound reduction in bleeding associated with LNG-IUS use not surprisingly results in sustained increases in hemoglobin, hematocrit, and serum ferritin. ${ }^{33}$ Long-term follow-up studies of LNG-IUS in healthy women have demonstrated favorable sustained increased from baseline in hemoglobin concentrations with a mean increase of $1.6 \mathrm{~g} / \mathrm{dL}$ after 5 years of use ${ }^{90}$ and $1.44 \mathrm{~g} / \mathrm{dL}$ after 7 years of use. ${ }^{31}$

\section{Endometrial protection during hormone replacement}

Use of the LNG-IUS provides endometrial protection in women receiving estrogen replacement therapy, and is an approved indication of the LNG-IUS in over 90 countries. ${ }^{81}$ In a randomized study of 40 perimenopausal women who received oral estradiol $2 \mathrm{mg}$ and either a LNG-IUS or levonorgestrel $250 \mu \mathrm{g}$ orally for the last 10 days of the cycle, ${ }^{91}$ bleeding disturbances gradually diminished in the LNG-IUS group, and $83 \%$ of women were amenorrheic by 12 months. No endometrial proliferation or atypia was apparent in any of the biopsy samples from either group. These favorable findings were corroborated by studies using the LNG-IUS in conjunction with sustained-release subdermal ${ }^{92,93}$ transdermal, ${ }^{94}$ and oral $^{91}$ estrogen delivery systems with 1 to 3 years of follow-up. Three further trials have reported the sustained endometrial protection effects of the LNG-IUS over 5 years. ${ }^{95-97}$

\section{Uterine myoma}

The LNG-IUS has been shown to reduce blood loss associated with fibroids, however there is less consistent data about its ability to reduce the size of fibroids or overall uterine dimensions. ${ }^{98}$ In a Russian study of 67 women with myomas, uterine size of $\leq 12$ weeks, and a normal uterine cavity, the LNG-IUS substantially reduced blood loss at 12 months, and decreased uterine and leimyomata size. ${ }^{99}$ Forty percent of these women were amenorrheic by 12 months, and all but 1 woman had hemoglobin concentrations of $>12 \mathrm{~g} / \mathrm{dL}$ by 12 months. A Turkish study enrolled 32 women with menorrhagia, at least one submucosal fibroid $<50 \%$ into the uterine cavity, and overall uterine volume $380 \mathrm{~mL}$ to receive a LNG-IUS. ${ }^{100}$ These subjects were followed for 12 months, and bleeding and hemoglobin levels were compared to 32 historical controls who underwent thermal balloon ablation. There was significant and similar improvement in bleeding and hemoglobin levels in both groups, and no changes in uterine volume or fibroid sizes.

There is also evidence of a potential preventive effect. Among women randomized to treatment with either the LNG-IUS or copper T380A, the incidence over 7 years of a new diagnosis of uterine myoma or myoma-related surgery was significantly lower in the LNG-IUS group. ${ }^{49}$

\section{Treatment of pelvic pain associated endometriosis and adenomyosis}

Several small pilot studies suggest that the LNG-IUS can be useful in the treatment of pelvic pain associated with endometriosis and adenomyosis. ${ }^{101-108}$ Two studies that evaluated postoperative insertion of a LNG-IUS resulted in a significant reduction in the symptoms of dysmenorrhea in women treated with laparoscopy for endometriosis. ${ }^{102,103}$ Another randomized study found that the improvement in pain and quality of life achieved in women with endometriosis with the LNG-IUS is comparable to that achieved with a GnRH agonist, even with Stage III/IV disease. ${ }^{104}$

Successful management of pain and abnormal bleeding associated with adenomyosis has also been reported. ${ }^{105,106}$ A Brazilian study of 29 women with adenomyosis showed a reduction in junctional zone thickness between endometrium and myometrium by magnetic resonance imaging (MRI), but no decrease in uterine volume. ${ }^{107} \mathrm{~A}$ recent Chinese study showed effectiveness in treating adenomyosis with 3 years of continuous use. ${ }^{108}$

\section{Treatment of endometrial hyperplasia and cancer}

A number of studies consistently have shown a decreased risk of endometrial cancer in IUD users compared to nonusers, however most studies did not specify the IUD types being investigated. ${ }^{109}$ 
A recent meta-analysis found a protective association between IUD use and endometrial cancer, with a pooled odds ratio of 0.54 (95\% CI 0.47 to 0.63$).{ }^{110}$ The mechanism by which copper and inert IUDs provide this protection is unclear. However, there is biologic plausibility that locally delivered LNG by the LNG-IUS would oppose estrogen related endometrial changes that lead to hyperplasia and cancer. ${ }^{111}$ Since systemic progestins are poorly tolerated by some patients, local progestin delivery can be an attractive alternative.

There is evidence of complete histological regression of endometrial hyperplasia with LNG-IUS treatment. ${ }^{112-115}$ A recent, non-randomized, Norwegian study compared LNGIUS, oral progestins and observation among 370 women with simple and atypical hyperplasia. In this study, the LNG-IUS showed superior resolution over oral progestins or observation, and there were no cases that progressed to cancer when followed to a maximum of 106 months. ${ }^{116}$

In women with proven early endometrial cancer, three case series have reported treatment with the LNG-IUS. These studies, which collectively include a total of 27 women with grade 1 endometrial carcinoma, have shown a regression rate of $25 \%$ to $75 \%$ after LNG-IUS exposure. ${ }^{117-119}$ Further studies are needed to determine the utility and safety of LNG-IUS for the treatment of endometrial cancer.

\section{Adjuvant therapy with tamoxifen}

Tamoxifen stimulates the uterus, and increases the risk of endometrial polyps, fibroids, hyperplasia ${ }^{120}$ and endometrial cancer. ${ }^{121}$ Results from a randomized trial determined that the LNG-IUS prevented the development of endometrial polyps or hyperplasia in patients receiving tamoxifen over 1 year of use. ${ }^{122}$ However, women who received the LNG-IUS also experienced more bleeding. Given the unproven safety of the LNG-IUS in breast cancer patients, longer-term randomized studies are needed to determine the benefit to risk balance in these patients. It is reassuring to note that population-based studies have not shown an increase in the risk of breast cancer among LNG-IUS users. ${ }^{123}$

\section{Summary}

The wide range of benefits of the LNG-IUS, in both contraception and treatment of gynecological disorders, will continue to make it an attractive option for women worldwide. Its contraceptive efficacy is excellent - comparable to, if not higher than, surgical sterilization, and it is reversible. In addition, it can offer women improvement in anemia, menorrhagia, endometriosis, control of uterine fibroids and adenomyosis, and protection against and treatment of endometrial hyperplasia and possibly early endometrial cancer. Because of its effectiveness, high patient acceptability and demonstrated safety, the LNG-IUS will continue to provide important benefits in women's reproductive health.

\section{Disclosures}

Dr Bednarek and Dr Jensen serve as consultants for Bayer HealthCare.

\section{References}

1. Peterson HB, Curtis KM. Long-acting methods of contraception. N Engl J Med. 2005;353:2169-2175.

2 Salem R. New Attention to the IUD: Expanding women's contraceptive options to meet their needs. Pop Rep, Series B, No. 7. Baltimore: Johns Hopkins Bloomberg School of Public Health, The INFO Project; 2006.

3. http://www.mirena-us.com/press_room/index.jsp. Accessed February 8, 2009.

4. United Nations. Department of Economic and Social Affairs. Population Division. World Contraceptive use in 2007. 2008; United Nations publication (ST/ESA/SER.A/273).

5. World Health Organization. Improving Access to Quality Care in Family Planning. Medical Eligibility Criteria for Contraceptive Use. 3rd ed. Geneva: WHO; 2004.

6. Grimes DA. Intrauterine devices and upper-genital tract infection. Lancet. 2000;356:1013-1019.

7. Hubacher D, Lara-Ricalde R, Taylor DJ, et al. Use of copper intrauterine devices and the risk of tubal infertility among nulligravid women. N Engl J Med. 2001;345:561-567.

8. Shelton JD. Risk of clinical pelvic inflammatory disease attributable to an intrauterine device. Lancet. 2001;357:443.

9. Nelson AL, Grimes D, Arias R, Shulman L, Moore A. Intrauterine copper contraceptive: update and opportunities. OBG Management. 2006;S1-S8.

10. Mirena [package insert]. Wayne, NJ: Bayer HealthCare Pharmaceuticals Inc. 2008. Available at: http://berlex.bayerhealthcare.com/html/ products/pi/Mirena_PI.pdf.

11. Nilsson CG, Lahteenmaki P, Robertson DN, Luukkainen T. Plasma concentrations of levonorgestrel as a function of the release rate of levonorgestrel from medicated intra-uterine devices. Acta Endocrinol. 1980;93:380-384.

12. Diaz S, Pavez M, Miranda P, Johansson EDB, Croxatto HB. Long-term follow-up of women treated with Norplant implants. Contraception. 1987;35:551-567.

13. Nilsson CG, Lahteenmaki PLA, Luukkainen T, Robertson DN. Sustained intrauterine release of levonorgestrel over five years. Fertil Steril. 1986;45:805-807

14. Nilsson CG, Haukkamaa M, Vierola H, et al. Tissue concentrations of levonorgestrel in women using a levonorgestrel-releasing IUD. Clin Endocrinol. 1982;17:529-536.

15. Perino A, Quartararo P, Catinella E, Genova G, Cittadini E. Treatment of endometrial hyperplasia with levonorgesterel releasing intrauterine devices. Acta Eur Fertil. 1987;18:137-140.

16. Zhu P, Luo H, Xu R, et al. The effect of intrauterine devices, the stainless steel ring, the Copper T220, and releasing levonorgestrel, on the bleeding profile and the morphological structure of the human endometrium - a comparative study of three IUDs: a morphometric study of 96 cases. Contraception. 1989;40:425-438.

17. Silverberg SG, Haukkamaa M, Arko H, Nilsson CG, Luukkainen T. Endometrial morphology during long-term use of levonorgestrel-releasing intrauterine devices. Int J Gynecol Pathol. 1986;5:235-241.

18. LuukkainenT, Lahteenmaki P, Toivonen J. Levonorgestrel-releasing intrauterine device. Ann Med. 1990;22:85-90. 
19. Xiao B, Zhou L, Zhang X, Jia M, Luukkainen T, Allonen H. Pharmacokinetic and pharmacological studies of levnorgestrel-releasing intrauterine device. Contraception. 1990;41:353-362.

20. Nilsson CG, Lahteenmaki PLA, Luukkainen T. Ovarian function in amenorrheic and menstruating users of a levonorgestrel-releasing intrauterine device. Fertil Steril. 1984;41:52-55.

21. Ortiz ME, Croxatto HB, Bardin CW. Mechanism of action of intrauterine devices. Obstet Gynecol Survey. 1996;51:S42-S53.

22. Sivin I. IUDs are contraceptives, not abortifacient: A comment on research and belief. Stud Fam Plan. 1989;20:355-359.

23. Barbosa I, Bakos O, Olsson S-E, Odlind V, Johansson EDB. Ovarian function during use of a levonorgestrel-releasing IUD. Contraception. 1990;42:51-66.

24. Munuce MJ, Nascimento JAA, Rosano G, Faundes A, Bahamondes L. Doses of levonorgestrel comparable to that delivered by the levonorgestrel-releasing intrauterine system can modify the in vitro expression of zona binding sites of human spermatozoa. Contraception. 2006;73:97-101.

25 Mandelin E, Koistinen H, Koistinen R, et al. Levonorgestrel-releasing intrauterine device-wearing women express contraceptive glycodelin A in endometrium during midcycle: another contraceptive mechanism? Hum Reprod. 1997;12:2671-2675.

26. Trussel J. Contraceptive failure in the United States. Contraception. 2004;70:89-96.

27. Backman T, Rauramo I, Huhtala S, Koskenvuo M. Pregnancy during the use of levonorgestrel intrauterine system. Am J Obstet Gynecol. 2004;190:50-54.

28 French R, Van Vliet H, Cowan F, et al. Hormonally impregnated intrauterine systems (IUSs) versus other forms of reversible contraceptives as effective methods of preventing pregnancy. Cochrane Database Syst Rev. 2004. CD001776.

29. Silverberg SG, Haukkamaa M, Arko H. Endometrial morphology during long-term use of levonorgestrel-releasing intrauterine devices. Int J Gynecol Pathol. 1986;5:235-241.

30. Barbosa I, Olsson SE, Odlind V, et al. Ovarian function after seven year's use of a levnorgestrel IUD. Adv Contracept. 1995;11:85-95.

31. Sivin I, Stern J, Coutinho E, et al. Prolonged intrauterine contraception: a seven-year randomized study of the levonorgestrel $20 \mathrm{mcg} /$ day ( $\mathrm{LNg} 20)$ and the Copper T380 Ag IUDS. Contraception. 1991;44:473-480.

32. Diaz J, Faundes A, Diaz M, Marchi N. Evaluation of the clinical performance of a levonorgestrel-releasing IUD, up to seven years of use, in Campinas, Brazil, Contraception. 1993;47:169-175.

33. Ronnerdag M, Odlind V. Health effects of long-term use of the intrauterine levonorgestrel-releasing system: a follow-up study over 12 years of continuous use. Acta Obstet Gynecol Scand. 1999;78:716-721.

34. Andersson K, Odlind V, Rybo G. Levonorgestrel-releasing and copperreleasing (Nova T) IUDs during five years of use: a randomized comparative trial. Contraception. 1994;49:56-72.

35. Belhadj H, Sivin I, Diaz S, et al. Recovery of fertility after use of the levonorgestrel $20 \mathrm{mcg} / \mathrm{d}$ or copper T 380Ag intrauterine device. Contraception. 1986;34:261-267.

36. Sivin I, Stern J, Diaz S, et al. Rates and outcomes of planned pregnancy after use of Norplant capsules, Norplant II rods, or levonorgestrelreleasing or copper Tcu 380Ag intrauterine contraceptive devices. Am J Obstet Gynecol. 1992;166:1208-1213.

37. Andersson K, Batar I, Rybo G. Return to fertility after removal of a levonorgestrel-releasing intrauterine device and Nova-T. Contraception. 1992;46:575-584.

38. Forrest JD. US women's perceptions of and attitudes about the IUD. Obstet Gynecol Surv. 1996;51:S30-S34.

39. Costales A, Jensen J, Nelson A, Korner P, Uddin M. A US multicenter, open-label trial with the levonorgestrel-releasing intrauterine system (LNG-IUS) - clinical and device-related experience. Contraception. 2006;74:178.

40. Backman T, Huhtala S, Blom T, et al. Length of use and symptoms associated with premature removal of the levonorgestrel intrauterine system: a nation-wide study of 17,360 users. BJOG. 2000;107:335-339.
41. Nascimento R, Bahamondes L, Hidalgo M, Perrotti M, EspejoArce X, Petta CA. Users' perspectives on bleeding patterns after two years of levonorgestrel-releasing intrauterine system use. Drugs $R D$. 2002;3(6):387-391.

42. Diaz J, Bahamondes L, Monteiro I, Petta C, Hildalgo MM, Arce XE. Acceptability and performance of the levonorgestrel-releasing intrauterine system (Mirena) in Campinas, Brazil. Contraception. 2000; 62:59-61.

43. Jensen JT, Nelson AL, Costales AC. Subject and clinician experience with the levonorgestrel-releasing intrauterine system. Contraception. 2008;77:22-29.

44. Mumford SD, Kessel E. Was the Dalkon Shield a safe and effective intrauterine device? The conflict between case-control and clinical trial study findings. Fertil Steril. 1992;57:1151-1176.

45. Farley TM, Rosenberg MJ, Rowe PJ, Chen J, Meirik O. Intrauterine devices and pelvic inflammatory disease: an international perspective. Lancet. 1992;339:785-788.

46. Simms I, Rogers $\mathrm{P}$, Charlett A. The rate of diagnosis and demography of pelvic inflammatory disease in general practice: England and Wales. Int J of STD and AIDS. 1999;10(7):448-451.

47. Westrom L. Incidence, prevalence, and trends of acute pelvic inflammatory disease and its consequences in industrialized countries. Am J Obstet Gynecol. 1980;138:880-892.

48. Toivonen J, Luukkainen T, Allonen H. Protective effect of intrauterine release of levonorgestrel on pelvic infection: three years' comparative experience of levonorgestrel- and copper-releasing intrauterine devices. Obstet Gynecol. 1991;77:261-264.

49. Sivin I, Stern J. Health during prolonged use of levonorgestrel 20 micrograms/d and the copper TCu 380Ag intrauterine contraceptive devices: a multicenter study. International Committee for Contraception Research (ICCR). Fertil Steril. 1994;61:70-77.

50. World Health Organization Task Force on the Prevention and Management of Infertility. Tubal infertility: Serologic relationship to past chlamydial and gonococcal infection. Sex Trans Dis. 1995;22:71-77.

51. Grimes DA, Schulz KF. Prophylactic antibiotics for intrauterine device insertion: a metaanalysis of the randomized controlled trials. Contraception. 1999;60:57-63.

52. Grimes DA. Intrauterine device and upper-genital tract infection. Lancet. 2000;356:1013-1019.

53. Soderberg G, Lindgren S. Influence of an intrauterine device on the course of an acute salpingitis. Contraception. 1981;24:137-143

54. Hubacher D, Lara-Ricalde R, Taylor DJ, Guerra-Infante F, GuzmanRodriguez R. Use of copper intrauterine devices and the risk of tubal infertility among nulligravid women. N Engl J Med. 2001;345:561-567.

55. Sivin I. Dose- and age-dependent ectopic pregnancy risks with intrauterine contraception. Obstet Gynecol. 1991:78;291-298.

56. Marchbanks PA, Annegers JE, Coulam CB, Strathy JH, Kurland LT. Risk factors for ectopic pregnancy. A population based study. JAMA. 1988;259:1823-1827

57. Andersson K, Ryde-Blomqvist E, Lindell K, Odlind V, Milsom I. Perforations with intrauterine devices: report from a Swedish survey. Contraception. 1998;57:251-255.

58. Hopkins MR, Agudelo-Suarez P, El-Nashar S, Creedon DJ, Rose CH, Famuyide AO. Term pregnancy with intraperitoneal levonorgestrel intrauterine system: a case report and review of the literature. Contraception. 2009;79:323-327.

59. Intrauterine Device and Adolescents. ACOG Committee Opinion no. 392. American College of Obstetricians and Gynecologists. Obstet Gynecol. 2007;110:1493-1495.

60. Otero-Flores JB, Guerrero-Carreno FJ, Vazquez-Estrada LA. A comparative randomized study of three different IUDs in nulliparous Mexican women. Contraception. 2003;67:273-276.

61. Lehtovirta P, Paavonen J, Heikinheimo O. Experience with the levonorgestrel-releasing intrauterine system among HIV-infected women. Contraception. 2007;75:37-39.

62. Castano PM. Use of intrauterine devices and systems by HIV-infected women. Contraception. 2007;75:S51-S54. 
63. Morrision CS, Sekadde-Kigondu C, Sinei SK, Weiner DH, Kwok C, Kokonya D. Is the intrauterine device appropriate contraception for HIV-infected women? BJOG. 2001;108(8):784-790.

64. Gomes MPV, Deitcher SR. Risk of venous thromboembolic disease associated with hormonal contraceptives and hormone replacement therapy: a clinical review. Arch Intern Med. 2004;164: 1965-1976.

65. Pisoni CN. Cuadrado MJ. Khamashta MA. Hunt BJ. Treatment of menorrhagia associated with oral anticoagulation: efficacy and safety of the levonorgestrel releasing intrauterine device (Mirena coil). Lupus. 2006;15:877-880.

66. Trieman K, Liskin L, Kols A, et al. IUDs: an update. Pop Rep. Series B, No. 6. Baltimore: Johns Hopkins School of Public Health Population Information Program; 1995. Available at: http://www.infoforhealth. org/pr/online.shtml\#b.

67. White MK, Ory HW, Rooks JB, et al. Intrauterine device termination rates and the menstrual cycle day of insertion. Obstet Gynecol. 1980;55:220-224.

68. Ortayli N, Bulut A, Sahin T, Sivin I. Immediate postabortal contraception with the levonorgestrel intrauterine device, Norplant, and traditional methods. Contraception. 2001;63:309-314.

69. World Health Organization. IUD insertion following termination of pregnancy: a clinical trial of the TCu 220C, Lippes loop D, and copper 7. Stud Fam Plann. 1983;14:99-108.

70. Jensen JT, Nelson AL, Costales AC. Subject and clinician experience with the levonorgestrel-releasing intrauterine system. Contraception. 2008;77:22-29.

71. Luukkainen T, Allonen H, Haukkamaa M, Holma P, Pyorala T, Terho J, et al. Effective contraception with the levonorgestrel-releasing intrauterine device: 12-month report of a European multicenter study. Contraception. 1987;36:169-179.

72. World Health Organization. IUD insertion following termination of pregnancy: a clinical trial of the TCu 220C, Lippes loop D, and copper 7. Stud Fam Plann. 1983;14:99-108.

73. Celen S, Moroy P, Sucak A, Aktulay A, Danisman N. Clinical outcomes of early postplacental insertion of intrauterine contraceptive devices. Contraception. 2004;69:279-282.

74. Hayes JL, Cwiak C, Goedken P, Zieman M. A pilot clinical trial of ultrasound-guided post-placental insertion of a levonorgestrel intrauterine device. Contraception. 2007;76:292-296.

75. Hubacher D, Reyes V, Lillo S, Zepeda A, Chen PL, Croxatto H. Pain from copper intrauterine device insertion: randomized trial of prophylactic ibuprofen. Contraception. 2006;195:1272-1277.

76. Saav I, Aronsson A, Marions L, Stephansson O, Gemzell-Danielsson K. Cervical priming with sublingual misoprostol prior to insertion of an intrauterine device in nulliparous women: a randomized controlled trial. Hum Reprod. 2007:22;2647-2652

77. Burkman R, Schlesselman JJ, Zieman M. Safety concerns and health benefits associated with oral contraception. Am J Obstet Gynecol. 2004;190:S5-S22.

78. Suvisaari J, Lahteenmaki P. Detailed analysis of menstrual bleeding patterns after postmenstrual and postabortal insertion of a copper IUD or a levonorgestrel-releasing intrauterine system. Contraception. 1996;54:201-208.

79. Hidalgo M, Bahamondes L, Perrotti M, Diaz J, Dantas-Monteiro C, Petta C. Bleeding patterns and clinical performance of the levonorgestrelreleasing intrauterine system (Mirena) up to two years. Contraception. 2002;65:129-132.

80. Glasier AF, Smith KB, van der Spuy ZM, et al. Amenorrhea associated with contraception-an international study on acceptability. Contraception. 2003;67:1-8.

81. MacIsaac L, Espey E. Intrauterine Contraception: The Pendulum Swings Back. Obstet Gynecol Clin N Am. 2007;34:91-111.

82. Irvine GA, Campbell-Brown MB, Lumsden MA, Heikkila A, Walker JJ, Cameron IT. Randomised comparative trial of the levonorgestrel intrauterine system and norethisterone for treatment of idiopathic menorrhagia. BJOG. 1998;105:592-598.
83. Milsom I, Andersson K, Andersch B, Rybo G. A comparison of flurbiprofen, tranexamic acid, and a levonorgestrel-releasing intrauterine contraceptive device in the treatment of idiopathic menorrhagia. Am J Obstet Gynecol. 1991;164:879-883.

84. Xiao B, Wu SC, Chong J, Zeng T, Han LH, Luukkainen T. Therapeutic effects of the levonorgestrel-releasing intrauterine system in the treatment of idiopathic menorrhagia. Fertil Steril. 2003;79:963-969.

85. Hurskainen R, Teperi J, Rissanen P, et al. Clinical outcomes and costs with the levonorgestrel-releasing intrauterine system or hysterectomy for treatment of menorrhagia: randomized trial 5-year follow-up. JAMA. 2004;291:1456-1463.

86. Clegg JP. Guest JF. Hurskainen R. Cost-utility of levonorgestrel intrauterine system compared with hysterectomy and second generation endometrial ablative techniques in managing patients with menorrhagia in the UK. Curr Med Res Opin. 2007;23:1637-1648.

87. Marjoribanks J, Lethaby A, Farquhar C. Surgery versus medical therapy for heavy menstrual bleeding. Cochrane Database of Syst Rev. 2006. CD003855.

88. Soysal M, Soysal S, Ozer S. A randomized controlled trial of levonorgestrel releasing IUD and thermal balloon ablation in the treatment of menorrhagia. Zentral Gynakol. 2002;124:213-219.

89. Busfield RA, Farquhar CM, Sowter MC, et al. A randomised trial comparing the levonorgestrel intrauterine system and thermal balloon ablation for heavy menstrual bleeding. BJOG. 2006;113:257-263.

90. Andersson K, Odlind V, Rybo G. Levonorgestrel-releasing and copper-releasing (Nova T) IUDs during five years of use: a randomized comparative trial. Contraception. 1994;49:56-72.

91. Andersson K, Stadberg E, Mattsson LA, Rybo G, Samsioe G. Intrauterine or oral administration of levonorgestrel in combination with estradiol to perimenopausal women - effects on lipid metabolism during 12 months of treatment. Int J Fertil Menopausal Stud. 1996;41:476-483.

92. Suhonen SP, Allonen HO, Lahteenmaki P. Sustained-release estradiol implants and a levonorgestrel-releasing intrauterine device in hormone replacement therapy. Am J Obstet Gynecol. 1995;172:562-567.

93. Suhonen S, Holmstrom T, Lahteenmaki P. Three-year follow-up of the use of a levonorgestrel-releasing intrauterine system in hormone replacement therapy. Acta Obstet Gynecol Scand. 1997;76:145-150.

94. Raudaskoski TH, Lahti EI, Kauppila AJ, Apaja-Sarkkinen MA, Laatikainen TJ. Transdermal estrogen with a levonorgestrel-releasing intrauterine device for climacteric complaints: clinical and endometrial responses. Am J Obstet Gynecol. 1995;172:114-119.

95. Hampton NR, Rees MC, Lowe DG, Rauramo I, Barlow D, Guillebaud J Levonorgestrel intrauterine system (LNG-IUS) with conjugated oral equine estrogen: a successful regimen for HRT in perimenopausal women. Hum Reprod. 2005;20:2653-2660.

96. Varila E, Wahlstrom T, Rauramo I. A 5-year follow-up study on the use of a levonorgestrel intrauterine system in women receiving hormone replacement therapy. Fertil Steril. 2001;76:969-973.

97. Suvanto-Luukkonen E, Kauppila A. The levonorgestrel intrauterine system in menopausal hormone replacement therapy: five-year experience. Fertil Steril. 1999;72:161-163.

98. Kaunitz A. Progestin-releasing intrauterine systems and leiomyoma. Contraception. 2007;75:S130-S133.

99. Grigorieva V, Chen-Mok M, Tarasova M, Mikhailov A. Use of a levonorgestrel-releasing intrauterine system to treat bleeding related to uterine leiomyomas. Fertil Steril. 2003;79:1194-1198.

100. Soysal S, Soysal M. The efficacy of levnorgestrel-releasing intrauterine device in selected cases of myoma-related menorrhagia: a prospective controlled trial. Gynecol Obstet Invest. 2005;59:29-35.

101. Fedele L, Bianchi S, Zanconato G, Portuese A, Raffaelli R. Use of a levonorgestrel-releasing intrauterine device in the treatment of rectovaginal endometriosis. Fertil Steril. 2001;75:485-488.

102. Vercellini P, Frontino G, De Giorgi O, Aimi G, Zaina B, Crosignani PG. Comparison of a levonorgestrel-releasing intrauterine device versus expectant management after conservative surgery for symptomatic endometriosis: a pilot study. Fertil Steril. 2003;80:305-309. 
103. Lockhat FB, Emembolu JO, Konje JC. The efficacy, side effects and continuation rates in women with symptomatic endometriosis undergoing treatment with an intrauterine administered progestogen (levonorgestrel): a 3 year follow-up. Hum Reprod. 2005;20:789-793.

104. Petta CA, Ferriani RA, Abrao MS, et al. Randomized clinical trial of a levonorgestrel-releasing intrauterine system and a depot GnRH analogue for the treatment of chronic pelvic pain in women with endometriosis. Hum Reprod. 2005;20:1993-1998.

105. Maia H Jr, Maltez A, Coelho G, Athayde C, Coutinho EM. Insertion of mirena after endometrial resection in patients with adenomyosis. J Am Assoc Gynecol Laparosc. 2003;10:512-516.

106. Fong YF, Singh K. Medical treatment of a grossly enlarged adenomyotic uterus with the levonorgestrel-releasing intrauterine system. Contraception. 1999;60:173-175.

107. Bragheto AM. Caserta N. Bahamondes L. Petta CA. Effectiveness of the levonorgestrel-releasing intrauterine system in the treatment of adenomyosis diagnosed and monitored by magnetic resonance imaging. Contraception. 2007;76:195-199.

108. Sheng J, Zhang WY, Shang JP, Lu D. The LNG-IUS study on adenomyosis: a 3-year follow-up study on the efficacy and side effects of the use of levonorgestrel intrauterine system for the treatment of dysmenorrheal associated with adenomyosis. Contraception. 2009;79:189-193.

109. Hubacher D, Grimes DA. Noncontraceptive health benefits of intrauterine devices: a systematic review. Obstet Gynecol Surv. 2002;57:120-128.

110. Beining RM, Dennis LK, Smith EM, Dokras A. Meta-analysis of intrauterine device use and risk of endometrial cancer. Ann Epidemiol. 2008;18:492-499.

111. Akhmedkhanov A, Zeleniuch-Jacquotte A, Toniolo P. Role of exogenous and endogenous hormones in endometrial cancer: review of the evidence and research perspectives. Ann N Y Acad Sci. 2001;943:296-315.

112. Vereide AB, Kaino T, Sager G, Arnes M, Orbo A. Effect of levonorgestrel IUD and oral medroxyprogesterone acetate on glandular and stromal progesterone receptors (PRA and PRB), and estrogen receptors (ER-alpha and ER-beta) in human endometrial hyperplasia. Gynecol Oncol. 2005.

113. Wildemeersch D, Dhont M. Treatment of nonatypical and atypical endometrial hyperplasia with a levonorgestrel-releasing intrauterine system. Am J Obstet Gynecol. 2003;188:1297-1298.
114. Varma R, Soneja H, Bhatia K, et al. The effectiveness of a levonorgestrel-releasing intrauterine system (LNG-IUS) in the treatment of endometrial hyperplasia - A long-term follow-up study. Eur J Obstet Gynecol. 2008;139:169-175.

115. Bahamondes L, Ribeiro-Huguet P, de Andrade KC, Leon-Martins O, Petta CA. Levonorgestrel-releasing intrauterine system (Mirena) as a therapy for endometrial hyperplasia and carcinoma. Acta Obstet Gynecol Scand. 2003;82:580-582.

116. Orbo A, Arnes M, Hancke C, Vereide AB, Pettersen I, Larsen K. Treatment results of endometrial hyperplasia after prospective D-score classification: A follow-up study comparing effect of LNGIUD and oral progestins versus observation only. Gynecol Oncol. 2008:111;68-73.

117. Dhar KK, NeedhiRajan T, Koslowski M, Woolas RP. Is levonorgestrel intrauterine system effective for treatment of early endometrial cancer? Report of four cases and review of the literature, Gynecol Oncol. 2005;97:924-927.

118. Montz FJ, Bristow RE, Bovicelli A, Tomacruz R, Kurman RJ. Intrauterine progesterone treatment of early endometrial cancer. Am JObstet Gynecol. 2002;186:651-657.

119. Signorelli M, Caspani G, Bonazzi C, Chiappa V, Perego P, Mangioni C. Fertility-sparing treatment in young women with endometrial cancer or atypical complex hyperplasia: a prospective single-institution experience of 21 cases. BJOG. 2009;116:114-118.

120. Kedar RP, Bourne TH, Powles TJ, et al. Effects of tamoxifen on uterus and ovaries of postmenopausal women in a randomised breast cancer prevention trial. Lancet. 1994;343:1318-1321.

121. van Leeuwen FE, Benraadt J, Coebergh JW, et al. Risk of endometrial cancer after tamoxifen treatment of breast cancer. Lancet. 1994;343:448-452.

122. Gardner FJ, Konje JC, Abrams KR, et al. Endometrial protection from tamoxifen stimulated changes by levonorgestrel-releasing intrauterine system: a randomised controlled trial. Lancet. 2000;356:1711-1717.

123. Backman T, Rauramo I, Jaakkola K, et al. Use of the levonorgestrelreleasing intrauterine system and breast cancer. Obstet Gynecol. 2005;106:813-817.

124. Trussell J. Contraceptive failure in the United States. Contraception. 2004;70:89-96.
International Journal of Women's Health

\section{Publish your work in this journal}

The International Journal of Women's Health is an international, peerreviewed open-access journal publishing original research, reports, reviews and commentaries on all aspects of women's healthcare including gynaecology, obstetrics, and breast cancer. Subject areas include: Chronic conditions (migraine headaches, arthritis, osteoporosis);

\section{Dovepress}

Endocrine and autoimmune syndromes; Sexual and reproductive health; Psychological and psychosocial conditions. The manuscript management system is completely online and includes a very quick and fair peer-review system. Visit http://www.dovepress.com/ testimonials.php to read real quotes from published authors. 